\title{
Effect of Educational Program on Head Nurses Negotiation Skills for Resolution of Conflict among Nurses in Intensive Care Units \\ Loly M. Abozied ${ }^{1}$, Fouada M. Shabaan ${ }^{2}$, Karima A. El-syaid ${ }^{3}$, Walaa M Eid ${ }^{4}$ \\ ${ }^{1}$ Assistant lecturer of Nursing Service Administration, Faculty of Nursing, Tanta University \\ ${ }^{2,3}$ Professor of Nursing Service Administration, Faculty of Nursing, Tanta University \\ ${ }^{4}$ Lecturer of Nursing Service Administration, Faculty of Nursing, Tanta University
}

\section{Abstract}

Background: Negotiation skills are qualities that allow two or more parties to reach a compromise. It includes abilities such as communication, persuasion, planning, and cooperating. Head nurse who understand the basic principles and skills of negotiation will be ready to deal successfully with conflicting situations and become strong negotiators. Aim: Determine effect of educational program on head nurses' negotiation skills for resolution of conflict among nurses in intensive care units. Method: Include all ICUs of Tanta University Main Hospitals and Emergency Hospital. Subjects: All $(\mathrm{N}=35)$ head nurses and nurses (N=300). Tools: Tool I: Head nurses knowledge about negotiation skills for resolution of conflict among nurses' questionnaire. Tool II: Existence of conflict among ICU nurses' questionnaire. Tool III: Head nurses self-assessment about practice of negotiation for resolution of conflict among nurses. Results: High percent (76.3\%) of ICU nurses existed high level and $13.7 \%$ and $10.0 \%$ had moderate and low levels of conflict respectively. Preprogram head nurses $74.3 \%$ showed poor level of total knowledge about negotiation skills, changed to $82.9 \%$ of them showed good level of knowledge post program. Head nurses $25.7 \%$ showed satisfactory level preprogram significantly changed to $88.6 \%$ at satisfactory level of total practice of negotiation skills for resolution of conflict among ICU nurses post program. Conclusion: Head nurses knowledge and practice about negotiation skills for resolution of conflict among ICU nurses were at low level at Tanta University Main Hospital and Emergency Hospital. Head nurses knowledge and practice improved significantly after attendance of program sessions. Recommendation: Conduct periodical training programs, workshops and seminars for head nurses to refresh their knowledge, and practice of negotiation skills for resolution of ICU nurses conflict.

Key words: Conflict, Intensive care units, Negotiation, Negotiation skills. 


\section{Introduction}

An Intensive Care Unit (ICU) is a specially staffed and equipped, separate and highly complex area of hospital dedicated to the management and monitoring of patients with lifethreatening illness and provide them with needed critical care ${ }^{(1)}$. Nurses working at ICUs are professional nurses with academic preparation, give care for each shift and deal with high technological and sophisticated equipment's. They have to cooperate with other members of health care team to provide high quality of patient care ${ }^{(2)}$. While, head nurse should be prepared with technical, conceptual, human and leadership skills for motivating nurses to achieve ICU goals. They should have the ability to manage time effectively and conducting efficient negotiation during nurses' discussions, team building and dealing with conflict ${ }^{(3)}$. Conflicts are inevitable part of daily life in ICU and it can be viewed as a negative and harmful phenomenon if not well managed ${ }^{(4,5)}$. Dealing with sophisticated equipment's, limited resources, over workload, and nursing shortage at ICU lead to stressful conflicting environment. Beside structure administrative policies and interaction with head nurse and physician can contribute to conflict ${ }^{(6,7)}$. Nurses conflict results from differences in values, ideas, goals or feeling of forced and perceives blockage and starts to resist it ${ }^{(8,9)}$. Conflict among nurses emerges from verity of sources including personal factor due to difference in age, experience, opinions and values, inappropriate personal estimation, errors in communication, lack of work justice and unclear job description ${ }^{(10)}$.

Conflict among nurses can be well managed through negotiation process by which two or more parties with different interests or perspectives attempt to reach agreement, resolve problem and produce desirable outcome using knowledge, time and power ${ }^{(11,12)}$. Negotiation is a powerful process affect nurses' decision aiming to send a message through head nurse to influence each other ${ }^{(13)}$. Head nurses at ICU need periodically to develop their negotiation skill to get the best deal, facilities problem solving, gain support and build nurses co-operative relationships ${ }^{(14)}$. Negotiations processes includes three phases: planning and preparation, bargaining phase and closing the deal phase.

Planning and preparation is the first step in the negotiation process. Head nurse gather information as possible regarding the issue to be negotiated, understand the issue from different perspective, discuss a lot with people for getting more clarity about the problem (15). While at, bargaining phase head nurse and 
conflicting nurse sharing information and start building the relationship. The basic strategy in this phase is to convince the other party of the appropriateness of demands and then persuading the other party to concede to those demands. It require the head nurse to have skills in active listing, emotional control, verbal communication, collaboration and team work, problem solving, decision making, and interpersonal skill ${ }^{(16)}$.

Active listening and communication skills depend on ability to pay attention to what a person is saying, listening carefully, showing interest and not interrupting. Head nurses active listening skill requires listening for the content, intent, and feeling of the other. As well as, head nurse to listen carefully to each party during negotiation, remain calm in difficult situation, encourage the other person to talk and promote their willingness to communicate. Also, provide clear and direct feedback and encourage information sharing by creating climate of trust and support ${ }^{(17,18)}$.

Collaboration and team work skill refer to ability to encourage nurses to act and work together as a team, foster collaborative atmosphere and reach on agreeable solution. Beside head nurse should encourage good performance between team nurses, accept new suggestions from others and maintain enthusiastic soul for all team nurses ${ }^{(19)}$. Supervision and appraisals skill enhance good understanding of team boundaries and the difference between nurses to rich their work team strengths and treat weakness points of nurses and maintain supportive work team environment $(20,21)$. Head nurses should keep emotion under control and follow the patience to create calm, supportive environment for the resolution of difference, resolve problems and reach to successful agreement ${ }^{(22)}$. Closing the deal is the last step in negotiation process; both parties achieve what they wanted. Head nurse restate what has agreed on verbally and in writing and thanks all participants for their contribution to successful negotiation ${ }^{(23)}$. The skillful head nurse in negotiation process who knows the basic principles of conflict resolution will be ready to deal successfully with these inevitable situations and has the ability to reach an agreement. Mastering negotiation skills are crucial to maintain quality of patient care, improving staff moral and patient safety. So, the designed education program is important for head nurses to improve their knowledge and practice of negotiation skills for resolution of existed conflict among nurses at ICUs.

\section{Aim of the study}

Determine effect of educational program on head nurses' negotiation skills for 
resolution of conflict among nurses in intensive care units.

\section{Research hypothesis}

After implementation of the educational program for head nurses, it is expected that head nurses' knowledge and negotiation skills for resolution of conflict among nurses will be improved.

\section{Subjects and Method}

\section{Study design}

Quasi experimental research design was used to achieve the aim of the present research. Such design fits the nature of the problem under analysis and investigation. A quasi - experimental is an empirical intervention study used to estimate the causal impact of an intervention on its target population without random assignment.

\section{Setting}

The study conducted in all ICUs of Tanta university Main hospital at Neurology, Cardiology, chest, General Medical, pediatric and neonates. Also, Emergency hospital Anesthesia and Medical Emergency ICUs were included in the study. The capacity of Main University Hospital contain (103) beds. Neurology contain 17 beds, cardiology 22 beds, chest 8 beds, General Medical 18 beds, pediatric 18 beds and neonates 20 incubators. The capacity of Emergency Anesthesia contains 24 beds and Medical Emergency contains 12 beds.

\section{Subjects}

The study subject consisted of all $(\mathrm{N}=35)$ head nurses and nurses ( $\mathrm{N}=300)$ working at mention ICU.

\section{Tools}

The data of the study collected using three tools:

\section{Tool 1: Head Nurses Knowledge about} Negotiation Skills for Resolution of Conflict among Nurses Questionnaire. This tool developed by the researcher guided by Mc-Clendon (2010) ${ }^{(24)}$, Torabi et al. (2010) ${ }^{(25)}$ and related literature ${ }^{(26-28)}$ to assess head nurse knowledge about negotiation skills for resolution of conflict among nurses . It included two parts:-

Part one: Characteristics of head nurses such as age, sex, marital status, number of children, residence, name of ICU, level of education, and years of experience.

Part two: Question (60) about head nurses knowledge of negotiation skills for resolution of conflict among ICU nurses inform of multiple choice, true \& false and match. These questions were classified into 6 categories as follows:-

- Negotiation process aspect, include 10question.

- Negotiation process phases, include 10question

- Conflict aspects include 10question

- Strategies for resolution of conflict, include10 question 
- Factor affecting existence of conflict include10 question

- Skills required for head nurses at phases of negotiation include 10 question.

\section{Scoring system:}

Head nurses answer scored by correct answer $=1$ and incorrect answer $=0$.

\section{Levels of head nurse knowledge}

Good level knowledge $>75 \%$

Fair level knowledge $60-75 \%$

Poor level knowledge $<60 \%$

\section{Tool II: Existence of Conflict among}

\section{ICU Nurses Questionnaire.}

This tool developed by the researcher guided by Obied and Ahmed $(2016)^{(29)}$ and related recent literature ${ }^{(30,31)}$. This tool used to assess existence of conflict among nurses in ICU. It included two parts as follows:-

Part one: Characteristics of nurses such as age, sex, marital status, number of children, residence, name of ICU, level of education, years of experience.

Part two: Questionnaire to assess existed conflict among nurses at ICU, divided into five subscales as follows: -

- Personal conflict.

- ICU work environment conflict.

- Administrative policies conflict.

- Nurse -Head nurse interaction conflict.

- Nurse - physician interaction conflict.

\section{Scoring system}

Nurses' responses rated by scoring of always exist $=2$, often exist $=1$ and not exist $=0$.

\section{Levels of existence of conflict}

High conflict $>75 \%$

Moderate conflict 60-75\%

Low conflict $<60 \%$

\section{Tool III: Head Nurses Self-Assessment} about Practice of Negotiation for Resolution of Conflict among Nurses.

This tool developed by the researcher guided by Ester and John (2010) ${ }^{(32)}$ and related literature (33-35). It included question related to head nurses' practice of negotiation skill at each phase of negotiation as follows:-

\section{1-Planning and preparation phase before negotiation}

\section{2- Bargaining phase during negotiation}

it divided into six subscales as follows:

- Active listening skill subscale.

- Verbal communication skill subscale.

- Collaboration and teamwork skill subscale.

- Problem solving and decision making skills subscale.

- Interpersonal skill subscale.

- Emotion control skill subscale.

3- After negotiation and closing the deal phase.

\section{Scoring system}

Responses of nurses measured by

Always done $=2$ 
Sometimes done $=1$

Never done $=0$

\section{Levels of head nurses' practice}

Satisfactory practice $>65$

Unsatisfactory practice $<65$

\section{Method}

1. Official permission was obtained from Tanta Faculty of Nursing responsible authorities for Tanta University Main hospitals to obtain the approval and assistance in data collection.

2. Ethical consideration: the aim of the study was explained to staff nurses and head nurses to gain their cooperation, verbal consent for their participation in the study was obtained and they had the right to withdrawal. They were informed that their information was kept confidential.

3. Tools II and III were presented to a jury from the area of specialty to check tools content validity.

4. The jury responses were represented in four points rating scale ranging from (4-1); 4= strongly relevant and $1=$ not relevant. Necessary modifications were done included clarification, omission of certain questions and adding others and simplifying work related words. The content validity of tool II was $95.65 \%$ and for tool III was $95.42 \%$

5. Reliability of tools was tested using Cronbach Alpha Coeffecient test, its value $=0.845$ for head nurse knowledge about negotiation skills for resolution of conflict among nurses questionnaire 0.892 for existence of conflict among ICU nurses questionnaire and 0.886 for head nurses self-assessment about practice of negation for resolution of conflict .

6. A pilot study was carried out before starting the actual data collection. It was carried out on 3 head nurses and 48 nurses who are not from the study subjects. The estimated time needed to fulfill tools was approximately 15 minutes.

\section{Data collection phase}

- Tool I head nurses' knowledge about negotiation skills for resolution of conflict among nurses questionnaire was used before and after implementation of the program.

- Tool II existence of conflict among ICU nurses questionnaire was used before the program

- Tool III head nurses' self-assessment about practice of negotiation for resolution of conflict among ICU nurses was used before and after implementation of the program.

- ICU head nurses were divided in 8 groups. The program time was 6 session; 1hours for each session. The program conducted for head nurses at their intensive care unit at Tanta University Main hospitals and 
Emergency Hospital.

- The appropriate time for data collection was according the type of work and workload for each unit. The data collection started from October 2019.

\section{Constructional of educational program}

The first step was the statement of instructional objectives derived from the existence of conflict among nurses and needs of the head nurses and literature review.

\section{Instructional objectives}

The main objective of the program is to improve ICU head nurses knowledge and practice regarding negotiation skills for resolution of conflict among ICU nurses.

\section{Specific objectives}

At the end of the program the head nurses should be knowledgeable about negotiation skills for resolution of conflict among ICU nurses and successfully practice it at Tanta University Main Hospitals ICU through:

- Determine aspect related to negotiation process definition, causes, type, styles approaches and factor affecting it.

-Enumerate negotiation process phases of planning and preparation, bargaining and close the deal phases

-Identify aspect related to conflict definition, causes and types of conflict.

-Discuss strategies for resolution of conflict among nurses.
-Explain factor affecting existence of conflict at intensive care unit

-Apply negotiation skills at phases of negotiation process.

\section{Program content}

The content was designed to provide knowledge and application related to negotiation skills to resolve conflict among ICU nurses. The program includes six sessions as follows:-

- Session (1) Negotiation process aspects

- Session (2) Negotiation process phases

- Session (3) Conflict aspects

- Session (4) Strategies for resolution of conflict among nurses

- Session (5) Factors affecting existence of conflict at intensive care unit.

- Session (6) Skills required for head nurses at phases of negotiation process

\section{Learning strategies}

Selection of teaching method was governed by studying the subjects' needs and content of the program. The methods used were lecture, group discussion, case study, example from work and real life situation.

\section{Teaching aids}

The teaching aids used for attainment of program objectives were data show, handouts, flow sheets, pens and papers. 


\section{Implementation of program}

The study was conducted on 35 head nurses divided into eight groups. The program time was 6 hours for each group. One session every day for 6 day, every session was 1hours .They preferred to start the session after finishing necessary work. The Program sessions' applications were held in the conference room and head nurses room at Tanta University Main hospital and Emergency hospital.

Head nurses were informed about the general objectives of program and each session .The researcher builds good relationship and gave a simple form of motivation to enhance their participation and more involvement in the program activities.

\section{Statistical analysis}

- Statistical presentation and analysis of the present study was conducted, using the mean, standard Deviation, paired student t-test, chi-square and Linear Correlation Coefficient [r]tests by SPSS V20.

\section{Results}

Table (1): Shows characteristics of head nurses. High percent (71.4\%) of head nurses aged $<40$ years, with age range 35 46 years and mean 37.94 \pm 2.91 . All head nurses were female. $94.3 \%$ of them were married, $91.4 \%$ had more than two children and $51.4 \%$ lived in rural area. Equal percent (20\%) of head nurses worked at ICU for cardiology and neonates. At ICU of anesthesia 14.3\%, general medical and pediatric $11.4 \%$, $8.6 \%$ for neurology and chest and $5.7 \%$ for medical emergency. All head nurses not attend education program about negotiation skill before. Head nurses 33 had bachelor degree of nursing and 2 had master degree of nursing. Head nurses 60 $\%$ had 15- $<20$ years of experience with range 12-24 and mean 16.40 2.72 .

Table (2): Represents characteristics of nurses. The age ranged 21 to 56 years old with mean $33.19 \pm 6.70$. Nurses $87.7 \%$ was female, $80 \%$ married, $66.3 \%$ had more than two children and $51.4 \%$ lived in rural area. Equal (14.7\%) percent of nurses worked at neurology and cardiology, and equal (13.3\%) worked at medical emergency and neonatal. While $16 \%$, $11.7 \%, 8.3 \%$ and $8 \%$ of ICU nurses worked at anesthesia ICU, general medical, pediatric and chest ICU departments respectively. Nurses $72 \%$ had associate degree and $28 \%$ had bachelor degree of nursing, while $43 \%$ had $5-<15$ years of experience with mean \pm SD $12.04 \pm 7.34$.

Figure (1): Shows levels of existed conflict among ICU nurses .High percent of ICU nurses had high levels of conflict and low percent had moderate and low levels of conflict. 
Table (3): Shows levels and mean ranking of existed conflict type among ICU nurses. High percent $(76.3 \%)$ of ICU nurses had high level of conflict, and low percent $(13.7 \%)$ and $(10 \%)$ respectively had moderate and low levels of conflict. The first ranking (1) mean 1.71 \pm 0.61 was for nurse physician interaction type of conflict followed by rank (2) ICU work environment conflict mean $1.70 \pm 0.62$.The personal conflict mean $1.68 \pm 0.61$ ranked third followed by administrative policies conflict mean $1.63 \pm 0.65$ ranked (4) and the last (5) ranked mean $1.61 \pm 0.68$ was for nurse -head nurse interaction conflict.

Figure (2): Shows level of head nurses' total knowledge about negotiation skills to resolve ICU nurses conflict pre and postprogram. Pre- program high percent of head nurses showed poor level of total knowledge about negotiation skills changed post program and they showed good level of knowledge.

Table (4): Represents levels of head nurses knowledge of each dimension of negotiation pre and post program. There were highly statistically significant improvement of levels of head nurses total knowledge for each negotiation dimension post program at $(\mathrm{p}<0.001)$. Preprogram majority $(82.9 \%)$ of head nurses showed poor knowledge level for negotiation aspects, Equal (80\%) of head nurses had poor knowledge level for conflict aspects and skills required for head nurse at phases of negotiation process. Head nurses $77.1 \%, 71.4 \%$, and $68.6 \%$ showed poor knowledge level of strategies for resolution of conflict among nurses, negotiation process phases and factor affecting existence of conflict at ICUs respectively.

While, post program majority $(88.6 \%)$ of head nurses showed good knowledge level for negotiation aspects, Equal (85.7\%) of head nurses also showed good knowledge level for negotiation process phases and skills required for head nurse at phases of negotiation process. High percent $(82.9 \%),(77.1 \%)$ and $(74.3 \%)$ of head nurses post program showed good knowledge level for items of strategies for resolution of conflict among nurses, conflict aspects and factor affecting existence of conflict at ICUs respectively.

Figure (3): Shows head nurses' levels of total practice of negotiation for resolution of nurses' conflict pre and post program. Preprogram minority of head nurses had satisfactory level changed to be have satisfactory level of total practice of negotiation for resolution of nurses conflict post program.

Table (5): Shows levels of head nurses of total practice of negotiation phases for resolution of nurses' conflict pre and post program. There were highly statistical significant improvement of head nurses 
level of total practice of negotiation phases at $(\mathrm{P}=<0.001)$. Preprogram head nurses $71.4 \%$ showed unsatisfactory level for practice of planning and preparation phase changed post program to be $85.7 \%$ showed satisfactory level . Beside, head nurses $77.1 \%$ showed unsatisfactory level for practice of bargaining phase preprogram changed post program to be 91.4\% showed satisfactory level . About two third $(65.7 \%)$ of head nurses showed unsatisfactory level for practice of closing the deal phase preprogram changed post program to be $88.6 \%$ showed satisfactory level .

Figure (4): Shows correlation between head nurses total knowledge and total practice about negotiation for resolution of conflict among ICU nurses pre and post program. There was statistically significant positive correlation between head nurses total knowledge and practice about negotiation for resolution of conflict among ICU nurses. 
Table (1): Characteristics of head nurses $(n=35)$

\begin{tabular}{|c|c|c|}
\hline Variables & $\mathrm{N}=35$ & $\%$ \\
\hline \multicolumn{3}{|l|}{ Age } \\
\hline$<40$ & 25 & 71.4 \\
\hline$\geq 40$ & 10 & 28.6 \\
\hline Range & \multicolumn{2}{|c|}{$35-46$} \\
\hline Mean \pm SD & \multicolumn{2}{|c|}{$37.94 \pm 2.91$} \\
\hline \multicolumn{3}{|l|}{ Sex } \\
\hline Female & 35 & 100 \\
\hline \multicolumn{3}{|l|}{ Marital Status } \\
\hline Married & 33 & 94.3 \\
\hline Single & 1 & 2.9 \\
\hline Divorced & 1 & 2.9 \\
\hline \multicolumn{3}{|l|}{ Number of children } \\
\hline 0 & 1 & 2.9 \\
\hline 1 & 2 & 5.7 \\
\hline$>2$ & 32 & 91.4 \\
\hline \multicolumn{3}{|l|}{ Residence } \\
\hline Urban & 17 & 48.6 \\
\hline Rural & 18 & 51.4 \\
\hline \multicolumn{3}{|l|}{ Name of ICU } \\
\hline Neurology & 3 & 8.6 \\
\hline Cardiology & 7 & 20.0 \\
\hline Chest & 3 & 8.6 \\
\hline $\begin{array}{l}\text { General } \\
\text { Medical }\end{array}$ & 4 & 11.4 \\
\hline Pediatrics & 4 & 11.4 \\
\hline Neonates & 7 & 20.0 \\
\hline Anesthesia & 5 & 14.3 \\
\hline $\begin{array}{l}\text { Medical } \\
\text { Emergency }\end{array}$ & 2 & 5.7 \\
\hline \multicolumn{3}{|l|}{ Level of education } \\
\hline $\begin{array}{l}\text { Bachelor Degree of } \\
\text { Nursing }\end{array}$ & 33 & 94.3 \\
\hline Master Degree & 2 & 5.7 \\
\hline \multicolumn{3}{|c|}{ Program attended about negotiation } \\
\hline Not attend & 35 & 100 \\
\hline \multicolumn{3}{|l|}{ Years of experience } \\
\hline$<15$ & & \\
\hline $15-<20$ & 21 & 60.0 \\
\hline$\geq 20$ & 6 & 17.1 \\
\hline Range & \multicolumn{2}{|c|}{$12-24$} \\
\hline Mean \pm SD & \multicolumn{2}{|c|}{$16.40 \pm 2.72$} \\
\hline
\end{tabular}


Table (2): Characteristics of ICU nurses $(n=300)$

\begin{tabular}{|c|c|c|}
\hline Variable & $\mathrm{N}=300$ & $\%$ \\
\hline \multicolumn{3}{|l|}{ Age } \\
\hline$<25$ & 24 & 8.0 \\
\hline $25-<35$ & 146 & 48.7 \\
\hline $35-<45$ & 110 & 36.7 \\
\hline$\geq 45$ & 20 & 6.7 \\
\hline Range & \multicolumn{2}{|c|}{$21-56$} \\
\hline Mean \pm SD & \multicolumn{2}{|c|}{$33.19 \pm 6.70$} \\
\hline \multicolumn{3}{|l|}{ Sex } \\
\hline Female & 263 & 87.7 \\
\hline Male & 37 & 12.3 \\
\hline \multicolumn{3}{|l|}{ Marital status } \\
\hline Married & 240 & 80.0 \\
\hline Single & 56 & 18.7 \\
\hline Divorced & 4 & 1.3 \\
\hline \multicolumn{3}{|l|}{ No. of children } \\
\hline 0 & 69 & 23.0 \\
\hline 1 & 32 & 10.7 \\
\hline$>2$ & 199 & 66.3 \\
\hline \multicolumn{3}{|l|}{ Residence } \\
\hline Urban & 145 & 48.3 \\
\hline Rural & 155 & 51.7 \\
\hline \multicolumn{3}{|l|}{ Name of ICU } \\
\hline Neurology & 44 & 14.7 \\
\hline Cardiology & 44 & 14.7 \\
\hline Chest & 24 & 8.0 \\
\hline Pediatric & 25 & 8.3 \\
\hline $\begin{array}{l}\text { General } \\
\text { Medical }\end{array}$ & 35 & 11.7 \\
\hline Anesthesia & 48 & 16.0 \\
\hline $\begin{array}{l}\text { Medical } \\
\text { Emergency }\end{array}$ & 40 & 13.3 \\
\hline Neonates & 40 & 13.3 \\
\hline \multicolumn{3}{|l|}{ Level of education } \\
\hline $\begin{array}{c}\text { Associate Degree of } \\
\text { nursing }\end{array}$ & 216 & 72.0 \\
\hline $\begin{array}{l}\text { Bachelor Degree of } \\
\text { nursing }\end{array}$ & 84 & 28.0 \\
\hline \multicolumn{3}{|c|}{ Year of experience (years) } \\
\hline$<5$ & 62 & 20.7 \\
\hline $5-<15$ & 129 & 43.0 \\
\hline $15-<25$ & 97 & 32.3 \\
\hline 25 or more & 12 & 4.0 \\
\hline Range & \multicolumn{2}{|c|}{$1-37$} \\
\hline Mean \pm SD & \multicolumn{2}{|c|}{$12.04 \pm 7.34$} \\
\hline
\end{tabular}




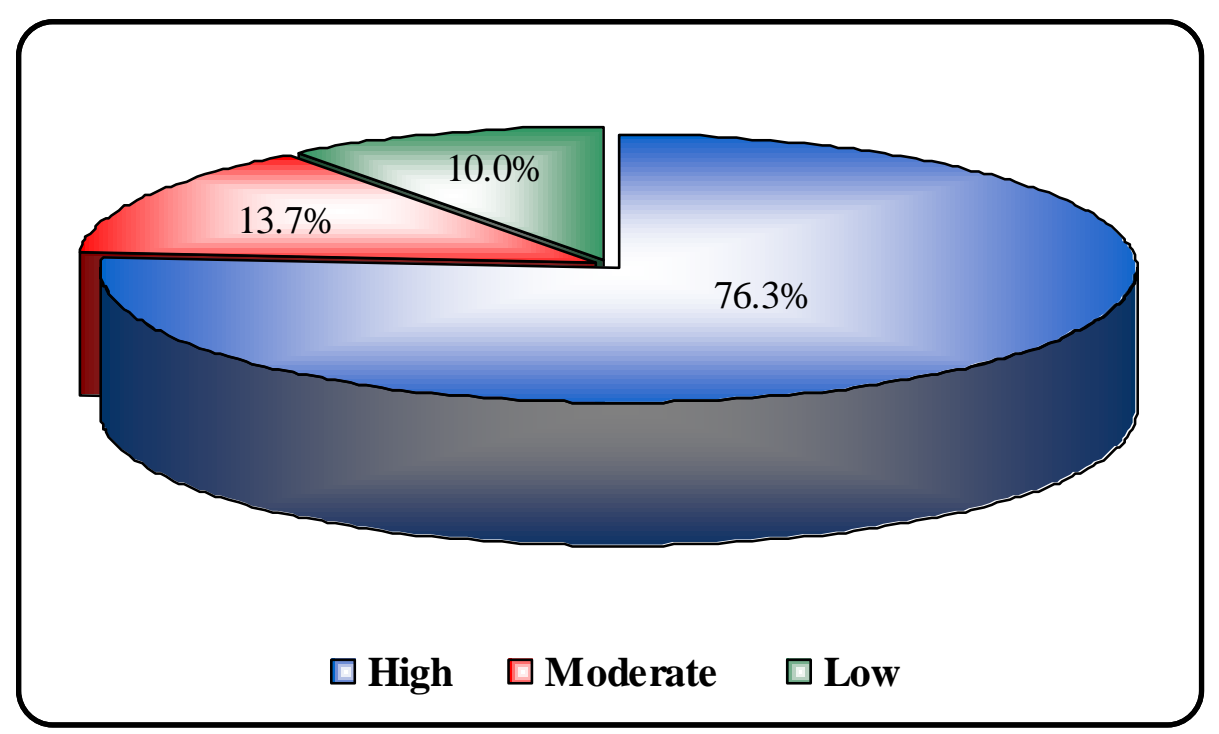

Figure (1): Levels of existed of conflict among ICU nurses (n=300)

Table (3): Levels, means and ranking of existed conflict type among ICU nurses $(\mathbf{n}=\mathbf{3 0 0})$

\begin{tabular}{|c|c|c|c|c|c|c|c|c|}
\hline \multirow{2}{*}{ Types of conflict } & \multicolumn{2}{|c|}{ High } & \multicolumn{2}{|c|}{ Moderate } & \multicolumn{2}{|c|}{ Low } & \multirow{2}{*}{$\begin{array}{l}\text { Mean } \\
\pm \text { SD }\end{array}$} & \multirow{2}{*}{$\begin{array}{r}\text { Ranking } \\
\text { of mean }\end{array}$} \\
\hline & $\mathbf{N}$ & $\%$ & $\mathbf{N}$ & $\%$ & $\mathbf{N}$ & $\%$ & & \\
\hline Personal conflict & 232 & 77.3 & 41 & 13.7 & 27 & 9.0 & $1.68 \pm 0.61$ & 3 \\
\hline $\begin{array}{l}\text { ICU work } \\
\text { environment conflict }\end{array}$ & 238 & 79.3 & 35 & 11.7 & 27 & 9.0 & $1.70 \pm 0.62$ & 2 \\
\hline $\begin{array}{l}\text { Administrative } \\
\text { policies conflict }\end{array}$ & 220 & 73.3 & 49 & 16.3 & 31 & 10.3 & $1.63 \pm 0.65$ & 4 \\
\hline $\begin{array}{l}\text { Nurse -Head nurse } \\
\text { interaction conflict }\end{array}$ & 218 & 72.7 & 44 & 14.7 & 38 & 12.7 & $1.61 \pm 0.68$ & 5 \\
\hline $\begin{array}{l}\text { Nurse -Physician } \\
\text { interaction conflict }\end{array}$ & 239 & 79.7 & 36 & 12.0 & 25 & 8.3 & $1.71 \pm 0.61$ & 1 \\
\hline
\end{tabular}




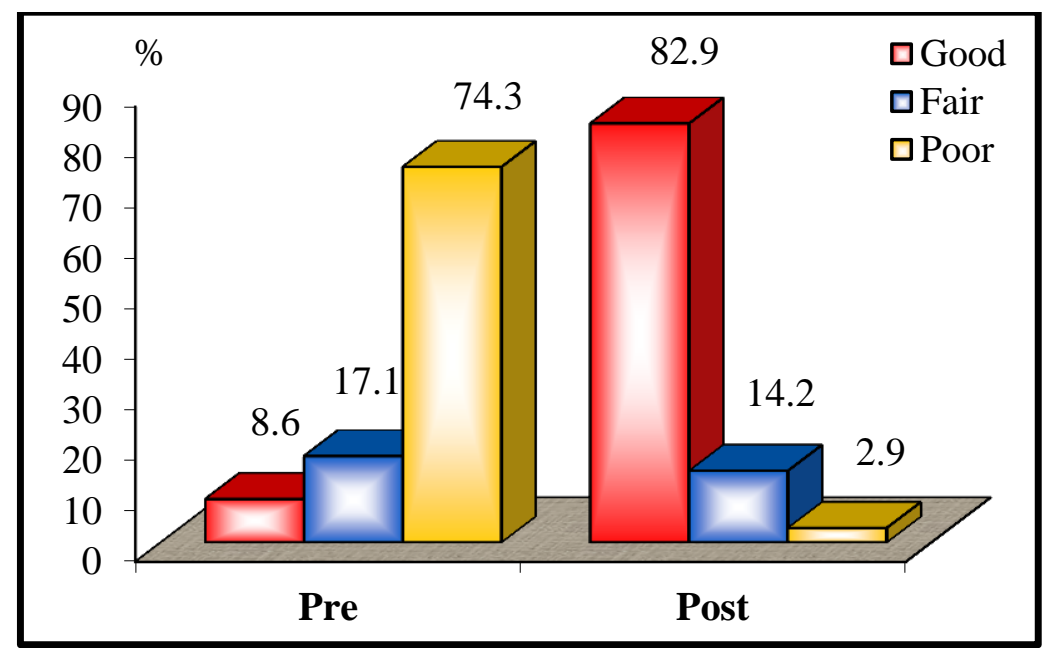

Figure (2): Levels of head nurses' total knowledge about negotiation to resolve ICU nurses conflict pre and post program $(n=35)$

Table (4): Levels of head nurses knowledge of each dimension of negotiation pre and post program $(n=35)$

\begin{tabular}{|c|c|c|c|c|c|c|c|c|c|c|c|c|c|}
\hline \multirow{4}{*}{$\begin{array}{l}\text { Levels } \\
\text { Dimension } \\
\text { knowledge }\end{array}$} & \multicolumn{12}{|c|}{$n=35$} & \multirow{4}{*}{$\underset{\text { P-value }}{\mathbf{X}^{2}}$} \\
\hline & \multicolumn{6}{|c|}{ Pre } & \multicolumn{6}{|c|}{ Post } & \\
\hline & \multicolumn{2}{|c|}{ Good } & \multicolumn{2}{|c|}{ Fair } & \multicolumn{2}{|c|}{ Poor } & \multicolumn{2}{|c|}{ Good } & \multicolumn{2}{|c|}{ Fair } & \multicolumn{2}{|c|}{ Poor } & \\
\hline & $\mathbf{N}$ & $\%$ & $\mathbf{N}$ & $\%$ & $\mathbf{N}$ & $\%$ & $\mathbf{N}$ & $\%$ & $\mathbf{N}$ & $\%$ & $\mathbf{N}$ & $\%$ & \\
\hline Negotiation & 2 & 5.7 & 4 & 11.4 & 29 & 82.9 & 31 & 88.6 & 3 & 8.6 & 1 & 2.9 & $\begin{array}{c}51.761 \\
<0.001 * *\end{array}$ \\
\hline $\begin{array}{l}\text { Negotiation } \\
\text { process }\end{array}$ & 5 & 14.3 & 5 & 14.3 & 25 & 71.4 & 30 & 85.7 & 4 & 11.4 & 1 & 2.9 & $\begin{array}{c}40.122 \\
<0.001^{* * *}\end{array}$ \\
\hline Conflict & 0 & 0.0 & 7 & 20.0 & 28 & 80.0 & 27 & 77.1 & 8 & 22.9 & 0 & 0.0 & $\begin{array}{c}55.067 \\
<0.001 * *\end{array}$ \\
\hline $\begin{array}{l}\text { Strategies of } \\
\text { resolution for } \\
\text { conflict }\end{array}$ & 3 & 8.6 & 5 & 14.3 & 27 & 77.1 & 29 & 82.9 & 6 & 17.1 & 0 & 0.0 & $\begin{array}{c}48.216 \\
<0.001 * *\end{array}$ \\
\hline $\begin{array}{lr}\text { Factor } & \text { for } \\
\text { existence } & \text { of } \\
\text { conflict } & \text { at } \\
\text { ICUs } & \\
\end{array}$ & 4 & 11.4 & 7 & 20.0 & 24 & 68.6 & 26 & 74.3 & 8 & 22.8 & 1 & 2.9 & $\begin{array}{c}37.360 \\
<0.001 * *\end{array}$ \\
\hline $\begin{array}{l}\text { Skills for head } \\
\text { nurse at } \\
\text { negotiation } \\
\text { process phases }\end{array}$ & 2 & 5.7 & 5 & 14.3 & 28 & 80.0 & 30 & 85.7 & 4 & 11.4 & 1 & 2.9 & $\begin{array}{c}49.749 \\
<0.001 * *\end{array}$ \\
\hline
\end{tabular}

** Highly significant at $\mathbf{p}<0.001$ 


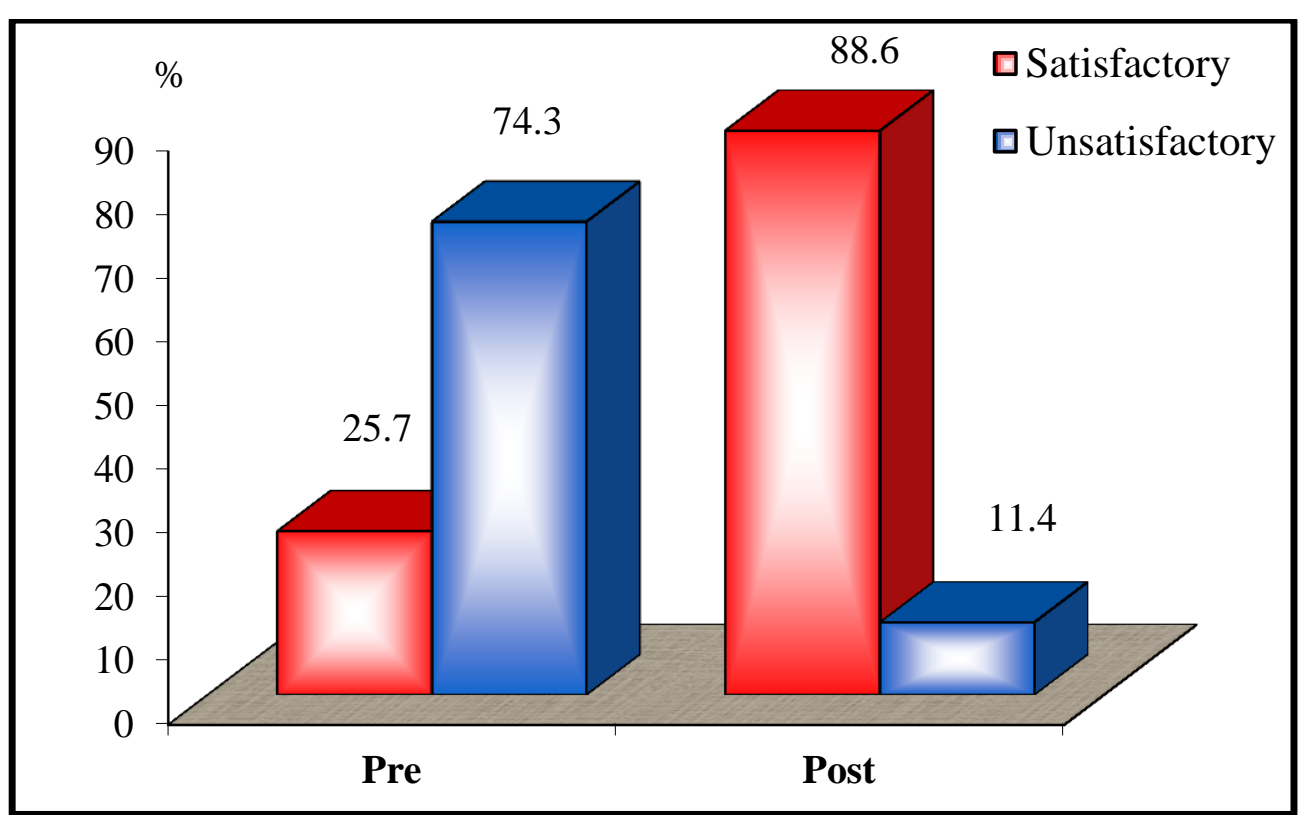

Figure (3): Head nurses levels of total practice of negotiation for resolution of conflict among ICU nurses pre and post program $(n=35)$

Table (5): Levels of head nurses total practice of negotiation phases for resolution of nurses conflict pre and post program $(n=35)$

\begin{tabular}{|c|c|c|c|c|c|c|c|c|c|}
\hline \multirow{3}{*}{$\begin{array}{l}\text { Levels } \\
\text { Negotiation } \\
\text { Practice phases }\end{array}$} & \multicolumn{4}{|c|}{ Pre } & \multicolumn{4}{|c|}{ Post } & \multirow{3}{*}{$\begin{array}{c}\mathrm{X} 2 \\
\text { p-value }\end{array}$} \\
\hline & \multicolumn{2}{|c|}{ Satisfactory } & \multicolumn{2}{|c|}{ Unsatisfactory } & \multicolumn{2}{|c|}{ Satisfactory } & \multicolumn{2}{|c|}{ Unsatisfactory } & \\
\hline & $\mathbf{N}$ & $\%$ & $\mathbf{N}$ & $\%$ & $\mathbf{N}$ & $\%$ & $\mathbf{N}$ & $\%$ & \\
\hline $\begin{array}{l}\text { 1-Planning and } \\
\text { preparation phase }\end{array}$ & 10 & 28.6 & 25 & 71.4 & 30 & 85.7 & 5 & 14.3 & $\begin{array}{r}23.333 \\
<0.001 * *\end{array}$ \\
\hline $\begin{array}{l}\text { 2-Bargaining } \\
\text { phase }\end{array}$ & 8 & 22.9 & 27 & 77.1 & 32 & 91.4 & 3 & 8.6 & $\begin{array}{c}33.600 \\
<0.001 * *\end{array}$ \\
\hline $\begin{array}{l}\text { 3-Closing the } \\
\text { deal phase }\end{array}$ & 12 & 34.3 & 23 & 65.7 & 31 & 88.6 & 4 & 11.4 & $\begin{array}{c}21.766 \\
<0.001 * *\end{array}$ \\
\hline
\end{tabular}

$* *$ Highly significant at $\mathbf{p}<0.001$ 

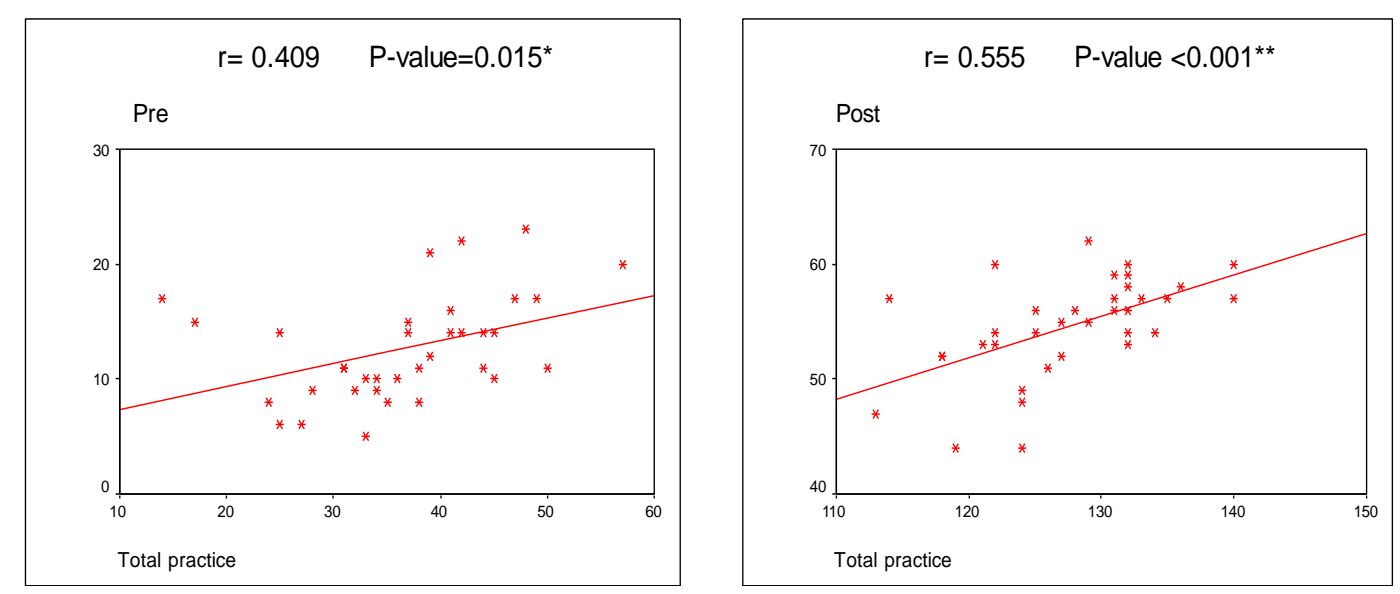

Figure (4): Correlation between head nurses total knowledge and total practice about negotiation for resolution of conflict among ICU nurse $(n=35)$ 


\section{Discussion}

Nurses at intensive care units play different roles such as care provider, educator, and manager. These many roles lead to various types of interactions among nurses and other health care team members, which significantly increase the probability for conflict to arise. Learning to manage conflict is one of the challenges ICU head nurses frequently face. Therefore head nurses need to be equipped with the necessary negotiation skills to manage nurses existed conflict. So, the designed education program is important for head nurses to improve their knowledge and practice of negotiation skills for resolution of existed conflict among nurses at ICU.

Study finding revealed that high percent of ICU nurses had high levels of conflict and low percent had moderate or low levels of conflict. Actually those nurses age, residence, level of education, years of experience and types of ICU showed significant impact on their level of conflict. In nursing profession conflict is natural and inevitable and arises as a daily challenge or contest between nurses with opposing needs, ideas, beliefs, values, or goals. Most properly their conflict to processes and contradictions brought about by their social changes, continued health system reforms, increasing demands and pressure to improve the productivity and quality of services provided. Sometimes conflict can inspire nurses to brainstorm ideas and examining problems from various perspectives.

Tosanolla et al. (2019) ${ }^{(36)}$ study causes of conflict between clinical and administrative staff in hospitals and Attia et al. (2019) ${ }^{(7)}$ study relationship between conflict and perception of professionalism among nurses working at Kafr Sakr General Hospital supported the present finding and showed that majority of nurses had high level of conflict due to nature and characteristics of work condition as heavy workload, resource shortage, inequalities in the organizational chart, remuneration and reward system, bureaucracy and poor management, poorly defined hierarchy relationship, different roles of a nurse and differences in goals among work groups and competition.

Also, Palyouz and Tsiotras (2018) study analysis of determinant factors of conflict in Greek hospital, revealed high percent of nurses conflict due to lack of organizational support, resource allocation issues, poor communication, and lack of experience. In addition other factors including workload in the workplace, weaknesses in hospital, competition among nurses or attitudes adoption, style of management of hospital manager and problematic behavior of patients. While, Mosadeghrad and Mojbafan (2019) ${ }^{(38)}$ study antecedents and consequences of 
conflict among nurse managers of Tehran University hospitals, reported that nurse managers experienced acceptable level of conflict, and consider conflict prerequisite to their attitude for positive changes and work progress.

Present study result revealed that high percent of head nurses preprogram implementation showed poor level of total knowledge about negotiation skills. As well as those head nurses showed poor knowledge about all dimension of negotiation especially negotiation skills of head nurses at its process phases and conflict dimensions. But post program they showed good level of knowledge for all dimensions of negotiation process. The fact is that those head nurses knowledge affected by their none attendance of previous orientation or training program about negotiation skill. So, they were unequipped with enough knowledge about many aspects of negotiation skills and conflict resolution.

Yet knowledge of most of those head nurses had significantly improved in majority of negotiation skills items immediately post program due to their ability to gain knowledge easily due to their level of education. Really, attendance of present program sessions gave them the opportunities to understand negotiation skills and strategies for resolution of conflict existed among ICU nurses. Most probably well-designed program attracted their attention to recognize the giving and receiving of communication and evoked their sense of responsibility and attracted them to be effective negotiators. Specially that the program clarified to them the benefits and outcomes of appreciating nurses different opinions, respect their preferences and to have attention to value their participation in group decision making.

Kamal and Mahfouz (2017) (39) study effect of education program about negotiation skills for head nurses on their time management, revealed that preprogram most of head nurses had poor negotiation skill knowledge. But, post program high percent of head nurses had good negotiation knowledge. Ahmed et al. (2016) $^{(40)}$ study about developing and implementing an educational program about strategies of conflict resolution for the head nurses working at Main Assuit University Hospital, showed that about two third of head nurses knowledge regarding the role of negotiator preprogram were unsatisfied, but head nurses knowledge at post implementation of the educational program was satisfactory.

Present study revealed that preprogram majority of head nurses had unsatisfactory level of total practice of negotiation for resolution of nurses conflict. Apparently the lack of knowledge of those head nurses 
about negotiation skills lead them to unsatisfactory level of practice. Actually they use improper communication technique and not use new technology for building effective work team. Indeed they have high need for education and training program for improving their negotiation skills.

Using of communication technique and technology in which head nurses teach their nurses to respect differences as an important part of team building and good communication, prime their nurses for positive thought, avoid negative thought wastes a lot of energy and usually doesn't accomplish anything. Head nurses teach their nurses that instead of complaining, they should be proactive and take initiative by doing so, they can actually make improvements happens. Also head nurse teach their nurses to acknowledge and recognize co-workers and be sure to offer them praise and encouragement.

Kamel and Mahfouz (2017) (39) support the present finding and revealed that head nurses' had higher negotiation skill at post program and there was a positive correlation among head nurses' negotiation knowledge and skills and head nurses practice negotiation and its technique that assist in development of stronger communication skills as useful tool in the management of hostile, threating, and insulting behaviors in a peaceful manner.
Also, those head nurses know the methods to balance between achieving own goals and respecting the need of others to improve clinical practice with better patient outcome. These finding supported by Hojjat et al. (2016) ${ }^{(41)}$ found that head nurses skills about negotiation was improved after training program implementation. It leads to increase in communication skills, increase interpersonal interaction with express feeling comfortable and understand each other better.

Current result revealed that preprogram high percent of head nurses showed unsatisfactory level of practicing planning and preparation phase of negotiation. Actually, those, head nurse not give attention to determine other party nurses' interests and positions leading to failing to find the best alternative negotiated agreement (BATNA). Even they not discuss the root cause of the problem with conflicted nurses. They overlook gathering all relevant information about the problem or identifying the basic need and benefits of negotiation for each party. Indeed those head nurses not recognize the value of good preparation for planning phase of negotiation. Besides, they do not care to put timeframe or manage time properly.

The result of present study was congruent with Zohar (2015) ${ }^{(42)}$ study the art of negotiation leadership skills required for 
negotiation in time of crisis, stated that in preparing, planning, and practicing, head nurse negotiator should use imagination to anticipate and predict what is needed and set justifiable regarding the outcome. Also, Ebrihim (2020) ${ }^{(43)}$ support the present finding and mentioned that head nurses in order to constructively negotiate and create win-win solution must be prepared well through making agenda for arranging ideas before negotiation begin. Moreover, the manner in which the head nurse manages the discussion and knows negotiation technique as well as understand each party's behavior and needs to deal is necessary for the success of negotiation process.

Results of current study clarified highly statistical significant improvement of head nurses level of practice of all skills of negotiation bargaining phase. Most probably after implementing the present program those head nurse become more knowledgeable to negotiate more effectively and express their feeling both verbally and non-verbally. They maintain balance between achieving goals, respecting need of others and creating winwin situation. Qureshi et al. (2018) (44) study is supervisors support matter in job satisfaction? A moderating role of fairness perception among nurses in Pakistan, stated that after implementation the program head nurses showed ability in leading ICU bring positive attitude and encourage climate of trust and respect.

The present study revealed that preprogram above one third of head nurses showed satisfactory level of total practice changed to be majority had satisfactory level of practice for closing the deal phase after negotiation post program. Preprogram head nurse, not follow principles of fairness with parties. They not sign the deal and not restate agreement verbally. They not offering solution and never recognize and thank all nurses participant for their contributions to successful negotiation. After head nurses attending present study educational program and trained to become effective in practicing negotiation skills, they succeed to be always to maintain good relationship with parties and reach the goal by offering suitable solutions.

Kamel and Mahfouz (2017) ${ }^{(39)}$ support the present study and revealed that there were highly statistical significant improvement in the head nurses' negotiation skills at closing the deal phase after intervention both post and follow up program. Their total mean scores for negotiation skill was low at pre-program and it improved at post and follow up program.

Yet immediately post program head nurses showed a high knowledge and skill regarding all items of negotiation. This 
indicated that education and training program has good effect on head nurses and helped them to manage existed nurses' conflicts at ICU. Apparently head nurses development of knowledge reflected on their practice for managing conflict and improving collaboration and good team work relations. They empowered to turn their negative behavior to positive one and maintain safe, satisfied, calm and enthusiastic work environment. They practice listening skills for understanding, reframing the causes of existed conflict among ICU nurses. Really head nurse understand how conflict develops and how to interact with all parties to discover effective solutions.

\section{Conclusion}

Most of nurses at Tanta Main and Emergency hospitals ICUs existed high level of conflict required the head nurses to resolve it using the negotiation skills. While the head nurses lacking knowledge of negotiation principles and cant satisfactory practice its skills preprogram. The present educational program explained to head nurses principles and skills of negotiation as well as trained them to be satisfactory practice it. The well designed and implemented program enforced their talents and significantly improving their knowledge and practice regarding negotiation skills for resolving the existed conflict among ICU nurses.

\section{Recommendations}

Based on the findings of the current study, the following recommendations can be suggested.

\section{- Hospital administrator}

1-Conduct periodical in-service training and -education programs for refreshing and developing head nurses knowledge and practice about the negotiation skills for resolution of conflict.

2-Encourage positive ICU work environment by providing of resources.

\section{-Head nurses}

3-Head nurses provide support and conductive clinical learning environment for ICU nurses.

4-Advertise posters containing tips about negotiation skills and principles at each ICU.

5-Head nurses promoting communication, cooperation and connection among ICU nurses.

6-Head nurses motivate nurses to express their opinions and personal rights.

7- Head nurses provide greater autonomy for nurses to participate in decision making.

8-Conduct educational program for nurses about causes of conflict and how to avoid it.

9-Encourage self-learning among ICU nurses to promote critical thinking and to use scientific methods to resolve conflict. 
10- Motivate nurses to participate in the development of new ideas to improve their communication in ICU.

\section{Recommendation for further research:}

11-Investigate the impact for using preventive measures on ICU nurses existence of conflict.

12-Investigate other methods for resolution of conflict among nurses.

\section{References}

1. Lafi K, Salem A. Nurses perceptions \& practices towards delirium in the intensive care units. Journal of Nursing and Health Science. 2018; 7(2):36-46.

2. Adam Sh, Osborne S, Welsh J. Critical Care Nursing. $3^{\text {rd }}$ ed. United Kingdom. Oxford University Co.; 2017. 2.

3. Moghaddam N, Zarger S, Rafiei S, Sarem A. Managerial competencies of head nurses: A model and assessment tool . British Journal of Nursing. 2019; 28 (1):30-37.

4. Ika C, Novieastari N, Nuraini T. The role of a head nurses in preventing interdisciplinary conflicts. Enferm Clinical Journal. 2019; 29(2):123-127.

5. Bakova S, Raykova E. Sources of conflict in public hospitals. Trakia Journal of Sciences. 2018; 16 (1): 117-121.

6. Boothe A, Frasier N, Weaver C, White J. Resolving conflict: What does the giraffe say? Journal of Nurse Leader. 2018; 2(16): 21-22.
7. A ttia A, Elsayed S, Ata A. Relation between conflict and perception of professionalism among nurses working at Kafr Sakr General Hospital. Zagazig Nursing Journal. 2019 ; 15 (2): 35-51.

8. Piryani R. Conflict management in health care. Journal of Nepal Health Research Council. 2019; 16 (41): 481-482.

9. Mayfeild L. Effect of conflict resolution education on nurse - nurse collaboration in a community hospital setting. Nursing Health International Journal. 2018; 2(6) : 1-16.

10. Abdl-Elraman E, Ghoneimy A. The effect of conflict management program on quality of patient care. American Journal of Nursing Science. 2018; 7(5):192-201.

11. Heavatay V, Nandhini K. Managing conflict negotiation and consensus. Journal of Nursing and Patient Safety Care. 2015; 1 (1): 19-24.

12. Adkoli B, Pawar S. Conflict management strategies implications for health professions education. Journal of Basic Clinical and Applied Health Science. 2018; 2(3):132:138.

13. Monney J, Adoms D, Yeboah A , Owusu A. Efficient conflict management strategies adopted by some heads of educational institutions in Ghana. International Journal of Scientific Research. 2017; 6(7): 532-538. 
14. Fleck D, Volkema R, Pereira S, Vaccari L. Factors affecting desire to negotiate again . Journal of Managerial psychology. 2017; 32(1): 16-29.

15. Tabassuma L. The importance of negotiation and conflict management. Journal of Management and Social Science. 2020; 2(4):15-19.

16. Azizollah A, Foroughameria G, Sarani H, Mahmoudi N. Assessment of head nurses' professional skills from head nurses' perspective. International Journal of Advanced biotechnology and Research. 2016; 7(5): 1836-1840.

17. Kohpeima V, Tabatabaee S, Abdar Z, Rajabi M. Active listening: The key of successful communication in hospital managers. Electronic Physician Journal. 2016; 8(3): 2123-2128.

18. Ibrahim Y, Ahamat A. Interpersonal communication skills of nurse managers and nursing performance. International Journal of Management Studies. 2019; 26(1): 99-145.

19. Wayne T, Mc-Cormac k. Using team building in a large inter professional Health Science Education Experience. Journal of Inter professional Education and Practice. 2016; 5(1): 19-21.

20. Shepared F, Stacey G, Aubeeluk A. The importance, impact and influence of group clinical supervision for graduate entry nursing students. Nurse
Education in Practice Journal. 2018; 28(1): 296-301.

21. Basa V. Supervisor - supervisee relationship and alliance. European Journal of Counseling Theory, Research and practice. 2017; 1(10):1-5.

22. Mohamed M, Fekry N. Relationship between head nurses emotional intelligence and staff nurses' job satisfaction. Medical Journal Cairo University. 2018; 86(7): 4065-72.

23. Elfering A, Gerhardt C, Grebner S, Müller U. Exploring supervisor-related job resources as mediators between supervisor conflict and job attitudes in hospital employees. Safe Health Work Journal. 2017; 8 (4):19-28.

24. Mc-Clendon B. The art of negotiation: What the twenty first century business student should know Western Carolina University. Journal of Legal Studies Education. 2010; 27(2): 277-319.

25. Torabi A, Ebrahimi B , Haghighzadeh M. Survey on relation between negotiating styles and conflict management strategies among the nursing managers in Ahvaz Hospitals. Journal of Health Science. 2010; 2(3):1212-1230.

26. Waithaka A, Austin S, Gitimu P. Influence of conflict resolution training on conflict handling styles of college students. Research in Higher Education 
Journal. 2015; 28(1):1-13.

27. Mick bin L. Conflict management important and implications. British Journal of Nursing. 2017; 26(2): 100-103.

28. Khalid S, Fatima I. Conflict types and conflict management styles in public and private hospital. Pakistan Armed Forces Medical Journal. 2016; 66(1):122-26.

29. Obied H, Ahmed S. Effect of utilizing conflict management strategies for ICU nurses on patient care. Journal of Nursing and Health Science. 2016; 5(2): 39-46.

30. Al shammari A, Dayarti R. Conflict and conflict resolution among the medical and nursing personnel of selected hospitals in Hilal City. Journal of Nursing and Health Science. 2017; 6(3): 45-60.

31. Zadeh M, Naderi M, Tafreshi M ,Zandi K. Factors affecting conflict among emergency nurses . Journal of Nursing Management. 2016; 5(2):18-25.

32. Ester L, John L. Communication skill work book: Self-assessment exercises \& educational handout. 2010. Available at: http:www.wholeperson .com.

33. Rees L, Kopelman S. Logics and Logistics for Future Research: Appropriately Interpreting the Emotional Landscape of Multicultural
Negotiation. Negotiation and Conflict Management Research. 2019; 12(2): 131-45.

34. Ebner N, Parlamis J. Weaving together theory, research, practice, and teaching: A four-dimensional approach to negotiation and conflict management work. Negotiation and Conflict Management Research. 2017; 10(4): 245-51.

35. Sebenius J. BATNAs in negotiation: Common errors and three Kinds. Negotiation Journal. 2017; 33(2): 89-99.

36. Tosanloo M, Adham D, Ahmadi B, Foroshani A, Pourreza A. Causes of conflict between clinical and administrative staff in hospitals. Journal of Education and Health Promotion. 2019; 8(1):191.

37. Polyzou M, Tsiotras G .Analysis of determinant factors of conflict in Greek Hospitals. International Journal of Caring Sciences. 2018; 11 (2): 935.

38. Mosadeghrad F, Mojbafan A . Antecedents and consequences of conflict among nurse managers of Tehran University hospitals. Journal of Medical. 2019; 20(4): 41-50.

39. Kamel F, Mahfouz H. Effect of education program about negotiation skills for head nurses on their time management. International Scientific Conference. 2017; 1-23. 
40. Ahmed H, Ibrahim $\mathrm{H}$, Yousef $\mathrm{R}$, Morsy S. Developing and implementing an educational program about strategies of conflict resolution for the head nurses working at Main Assuit University Hospital. Journal of Nursing and Health Science. 2016; 5(4): 33-43.

41. Hojjat S, Golmakani A, Khalili M, Chenarani N. The effectiveness of group assertiveness training on happiness in rural adolescent females with substance abusing parents. Global Journal of Health Science. 2016; 8(2): 156-164.

42. Zohar I. The art of negotiation Leadership skills required for negotiation in time of crisis. International Conference Education, Reflection, Development, Social and Behavioral Sciences Journal. 2015; 209(20): $540-8$.

43. Ebrahim E. Negotiation as a management strategy for conflict resolution and its effect on enhancing collaboration between nurses and physicians. Egyptian Nursing Journal. 2020; 17(1):13-22.

44. Qureshi M, Hamid K, Heihoony P, Ali A, Brohi N, Magsi R. Is supervisor support matter in job satisfaction? A moderating role of fairness perception among nurses in Pakistan. Academy of
Strategic Management Journal. 2018: 17(6): 1-10. 